\title{
Pengamanan Data File Teks (Word) Menggunakan Algoritma RC4
}

\author{
Dedy Ronald Saragi, Janter Manuel Gultom, Jose Andreas Tampubolon, Indra Gunawan \\ STIKOM Tunas Bangsa Pematangsiantar, Indonesia \\ Email: dedyronalsaragi@gmail.com, jantermanuel243@gmail.com,josetampubolon28@gmail.com, \\ indra@amiktunasbangsa.ac.id
}

\begin{abstract}
Abstrak-Keamanan data pada komputer dapat memberikan sebuah perlindungan terhadap data kita.Teknik kriptografi merupakan teknik yang sangat penting dalam mengamankan data. Kriptografi adalah ilmu mengenai teknik enkripsi dimana "naskah asli" (plaintext) diacak menggunakan suatu kunci enkripsi menjadi "naskah acak yang sulit dibaca" (ciphertext) oleh seseorang yang tidak memiliki kunci dekripsi, salah satu metode kriptografi modern yang dikembangkan adalah algoritma RC4. Algoritma RC4 (Ron's Code / Rivest's Cipher) adalah salah satu algoritma yang dapat digunakan untuk melakukan enkripsi data sehingga data asli hanya dapat dibaca oleh seseorang yang memiliki kunci enkripsi tersebut.
\end{abstract}

Kata Kunci: Algoritma RC4, Kriptografi, Enkripsi, Dekripsi

Abstract-Data security on computers can provide a protection for our data. Cryptographic techniques are very important techniques in securing data. Cryptography is the science of encryption techniques where the "original text" (plaintext) is encrypted using an encryption key into "random text that is difficult to read" (ciphertext) by someone who does not have a decryption key, one of the modern cryptographic methods developed is the RC4 algorithm. RC4 algorithm (Ron's Code / Rivest's Cipher) is one algorithm that can be used to encrypt data so that the original data can only be read by someone who has the encryption key.

Keywords: RC4 Algorithm, Cryptography, Encryption, Decryption

\section{PENDAHULUAN}

Proses perkembangan teknologi pada saat ini sangatlah pesat,memanipulasi terhadap teks atau berkas-berkas termasuk dokumen sangat lah mudah dilakukan. Pemalsuan terhadap dokumen umumnya dilakukan dengan cara memanipulasi isi dari dokumen baru dengan desain dan tampilan yang serupa dengan aslinya.Untuk menjaga kerahasian informasi tesebut adalah dengan menyamarkan menjadi bentuk tersandi yang bermakna.

Kriptografi pada awalnya dijabarkan sebagai ilmu yang mempelajari bagaimana menyembunyinkan pesan. Namun pada pengertian modern kriptografi adalah ilmu yang berdasarkan pada teknik matematika untuk berurusan dengan keamanan informasi seperti kerahasiaan, keutuhan data dan otentikasi entitas. Jadi pengertian kriptografi modern adalah tidak saja berurusan hanya dengan penyembunyian pesan namun lebih pada sekumpulan teknik yang menyediakan keamanan informasi [1].

Algoritma yang berfungsi untuk melakukan tujuan kriptografis disebut sebagai algoritma sandi. Algoritma tersebut harus memiliki kekuatan untuk melakukan [2]:

a. Konfusi/pembingungan, mempersulit pembaca biasa untuk memecahkan pesan yang sudah dienkripsi menjadi sandi-sandi tanpa memakai algoritma pendekripsinya.

b. Difusi/peleburan,yaitu dengan cara menghilangkan karakteristik dari informasi yang dienkripsi.

Algoritma kriptografi yang akan digunakan pada penelitian ini adalah algoritma simetris yaitu Rivest Code 4 (RC4). Algoritma RC4 adalah algoritma yang bersifat stream cipher dimana proses penyandiannya berorientasi pada satu bit/ byte data [3].

Algoritma dari metode RC4 Stream Cipher ini terbagi menjadi dua bagian, yaitu : key setup dan stream generation. Pada Key Setup terdapat tiga tahapan proses di dalamnya, yaitu Inisialisasi S-Box, Menyimpan key dalam Key Byte Array, Permutasi pada S-Box. Pada Stream Generation akan menghasilkan nilai pseudorandom yang akan dikenakan operasi XOR untuk menghasilkan ciphertext ataupun sebaliknya yaitu untuk menghasilkan plaintext.

\section{METODE PENELITIAN}

\subsection{Kriptografi}

Kriptografi penting dalam dunia teknologi informasi saat ini terutama dalambidang komputer yang mempelajari teknik-teknik matematika yang berhubungan dengan aspek keamanan informasi. Kriptografi juga menjadi salah satu syarat penting dalam keamanan teknologi informasi dalam pengiriman pesan penting dan rahasia.

Tujuan Kriptografi

1. Kerahasiaan (confidentiality)

Kerahasiaan adalah layanan yang digunakan untuk menjaga informasi dari setiap pihak yang tidak berwenang untuk mengaksesnya. Dengan demikian informasi hanya akan dapat diakses oleh pihak-pihak yang berhak saja.

2. Integritas data (data integrity) 
Integritas data merupakan layanan yang bertujuan untuk mencegah terjadinya pengubahan informasi oleh pihak-pihak yang tidak berwenang. Untuk meyakinkan integritas data ini harus dipastikan agar sistem informasi mampu mendeteksi terjadinya manipulasi data. Manipulasi data yang dimaksud meliputi penyisipan, penghapusan, maupun penggantian data.

3. Keaslian (authentication)

Keaslian merupakan layanan yang terkait dengan pembuktian identifikasi terhadap pihak-pihak yang ingin mengakses sistem informasi (entity authentication) maupun pembuktian data dari sistem informasi itu sendiri (data origin authentication).

4. Ketiadaan penyangkalan (non-repudiation)

Ketiadaan penyangkalan merupakan layanan yang berfungsi untuk mencegah entitas yang berkomunikasi melakukan penyangkalan, yaitu pengiriman pesan menyangkal melakukan pengiriman atau penerima pesan menyangkal telah menerima pesan.

Mekanisme Kriptografi

1. Plaintext (message) merupakan pesan asli yang ingin dikirimkan dan dijaga keamanannya.

2. Chipertext merupakan pesan yang telah dikodekan atau disandikan sehingga siap untuk dikirimkan.

3. Cipher merupakan algoritma matematis yang digunakan untuk proses penyandian plaintext menjadi ciphertext.

4. Enkripsi (encryption) merupakan proses yang dilakukan untuk menyandikan plaintext sehingga menjadi chipertext.

5. Dekripsi (decryption) merupakan proses yang dilakukan untuk memperoleh kembali plaintext dari ciphertext.

6. Kriptosistem merupakan sistem yang dirancang untuk mengamankan suatu sistem informasi dengan memanfaatkan kriptografi.

Prosesnya pada dasarnya sangat sederhana. Sebuah plaintext $(\mathrm{m})$ akan dilewatkan pada proses enkripsi (E) sehingga menghasilkan suatu ciphertext (c). Kemudian untuk memperoleh kembali plaintext, maka ciphertext (c) melalui proses dekripsi(D) yang akan menghasilkan kembali plaintext (m). Kriptografi modern selain memanfaatkan algoritma juga menggunakan kunci $(k e y)$ untuk memecahkan masalah tersebut dengan (e)= kunci enkripsi dan $(\mathrm{d})=$ kunci dekripsi. Mekanisme kriptografi seperti ini dinamakan kriptografi berbasis kunci. Dengan demikian kriptosistemnya akan terdiri atas algoritma dan kunci, beserta segala plaintext dan ciphertextnya. Proses enkripsi dan dekripsi dilakukan dengan menggunakan kunci ini yang digambarkan seperti pada Gambar 1.

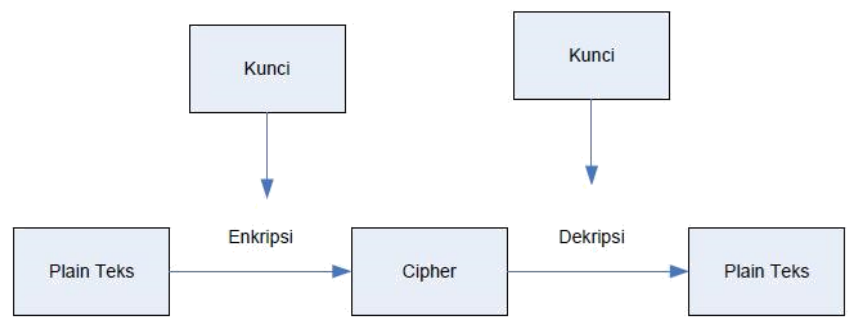

Gambar 1. Kriptografi Berbasis Kunci

Dokumen merupakan data yang sangat penting baik itu berupa dokumen pribadi, perusahaan atau organisasi dan lain sebagainya. Oleh karena itu, sebuah dokumen seharusnya dijaga kerahasiaannya agar tidak disalahgunakan oleh orang yang tidak berhak. Disini seringkali masalah keamanan menjadi urutan kedua atau bahkan urutan yang terakhir dalam daftar hal yang dianggap penting. Disini seringkali masalah keamanan menjadi urutan kedua atau bahkan urutan yang terakhir dalam daftar hal-hal Apabila menggangu performa sistem, masalah keamanan ini sering dikurangi atau bahkan dihilangkan.

Salah satu cara untuk mengamankan sebuah dokumen yaitu dengan mengubah dokumen asli menjadi dokumen yang tidak bisa dibaca oleh orang lain atau sering disebut dengan menggangu performa sistem, masalah keamanan ini sering dikurangi atau bahkan dihilangkan. Salah satu cara untuk mengamankan sebuah dokumen yaitu dengan mengubah dokumen asli menjadi dokumen yang tidak bisa dibaca oleh orang lain atau sering disebut dengan enkripsi.

\subsection{RC4 (Rivest Chiper 4)}

RC4 (Rivest Chiper 4) adalah sebuah synchrone stream chiper, yaitu cipher yang memiliki kunci simetris dan mengenkripsi plainteks secara digit per digit atau byte per byte dengan cara mengkombinasi dengan operasi biner dengan sebuah angka semi acak [2].

Tahap pencarian RC4. Byte keluaran dipilih dengan mencari nilai-nilai S [i] dan S [j], menambahkan mereka bersama-sama modulo 256, dan kemudian menggunakan jumlah sebagai indeks ke dalam S; S (S [i] + $\mathrm{S}$ [j]) digunakan sebagai byte dari stream kunci, $\mathrm{K}$. 


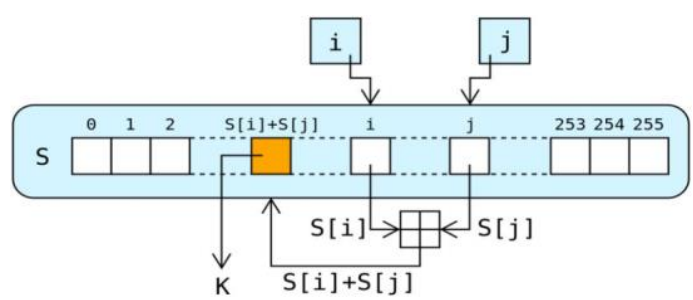

Gambar 2. Kunci Byte Pengeluaran Modula

Untuk sebanyak mungkin iterasi yang diperlukan, PRGA memodifikasi state dan menghasilkan byte byte keystream. Dalam setiap iterasi, PRGA:

1. Kenaikani i

2. mencari elemenke- i dari S, S [i], dan menambahkannya ke j

3. menukar nilai $\mathrm{S}$ [i] dan $\mathrm{S}$ [j] kemudian menggunakan jumlah $\mathrm{S}$ [i] $+\mathrm{S}$ [j] (modulo 256) sebagai indeks untuk mengambil elemen ketiga $S$ (nilai keystream $\mathrm{K}$ di bawah)

4. kemudian bitwise eksklusif ORed (XORed) dengan byte pesan berikutnya untuk menghasilkan byte berikutnya baik ciphertext atau plaintext.

Setiap elemen S ditukar dengan elemen lain setidaknya sekali setiap 256 iterasi.

$\mathrm{I}:=0$

$\mathrm{J}:=0$

Saat generating output ;

$\mathrm{I}:=(\mathrm{i}+1) \bmod 256$

$\mathrm{J}:=(\mathrm{j}+\mathrm{S}[\mathrm{i}]) \bmod 256$

Nilai swap $S$ [i] dan $S$ [j]

$\mathrm{K}:=\mathrm{S}[(\mathrm{S}[\mathrm{I}]+\mathrm{S}[\mathrm{j}]) \bmod 256]$

Keluaran K

Endwhile

Untuk menunjukkan cara kerja dari algoritma RC4 dapat dilihat dalam blok diagram pada Gambar 4. RC4menggunakan dua buah kotak substitusi (S-Box) array 256 byte yang berisi permutasi dari bilangan 0 sampai 255 dan S-Box kedua yang berisi permutasi fungsi dari kunci dengan panjang yang variabel. Cara kerja algoritma RC4 yaitu inisialisasi Sbox pertama, S[0],S[1],..,S[255], dengan bilangan 0 sampai 255.Pertama isi secara berurutan $\mathrm{S}[0]=0, \mathrm{~S}[1]=1, \ldots, \mathrm{S}[255]=255$. Kemudian inisialisasi array lain (S-Box lain), misal array $\mathrm{K}$ dengan panjang 256. Isi array $\mathrm{K}$ dengan kunci yang diulangi sampai seluruh array $\mathrm{K}[0], \mathrm{K}[1], \ldots, \mathrm{K}[255]$ terisi seluruhnya.

Berikut ini proses bagian dari metode RC4 [2]

1. Key Setup atau Key Schedulling Algorithm (KSA)

Pada bagian ini terdapat tiga tahapan proses di dalamnya yaitu:

a. Inisialisasi S-Box

Pada tahapan ini S-Box akan diisi dengan nilai sesuai indeksnya untuk mendapatkan S-Box awal.

Algoritmanya adalah sebagai berikut :

- untuk $\mathrm{i}=0$ hingga $\mathrm{i}=255$ lakukan,

- isikan s dengan nilai $\mathrm{i}$,

- tambahkan i dengan 1, kembali ke langkah 2.

Dari algoritma tersebut akan didapat urutan nilai S-Box yang direpresentasikan dalam Gambar 3.

\begin{tabular}{|c|c|c|c|c|c|c|c|c|c|c|c|c|c|c|c|}
\hline 0 & 1 & 2 & 3 & 4 & 5 & 6 & 7 & 8 & 9 & 10 & 11 & 12 & 13 & 14 & 15 \\
\hline 16 & 17 & 18 & 19 & 20 & 21 & 22 & 23 & 24 & 25 & 26 & 27 & 28 & 29 & 30 & 31 \\
\hline 32 & 33 & 34 & 35 & 36 & 37 & 38 & 39 & 40 & 41 & 42 & 43 & 44 & 45 & 46 & 47 \\
\hline 48 & 49 & 50 & 51 & 52 & 53 & 54 & 55 & 56 & 57 & 58 & 59 & 60 & 61 & 62 & 63 \\
\hline 64 & 65 & 66 & 67 & 68 & 69 & 70 & 71 & 72 & 73 & 74 & 75 & 76 & 77 & 78 & 79 \\
\hline 80 & 81 & 82 & 83 & 84 & 85 & 86 & 87 & 88 & 89 & 90 & 91 & 92 & 93 & 94 & 95 \\
\hline 96 & 97 & 98 & 99 & 100 & 101 & 102 & 103 & 104 & 105 & 106 & 107 & 108 & 109 & 110 & 111 \\
\hline 112 & 113 & 114 & 115 & 116 & 117 & 118 & 119 & 120 & 121 & 122 & 123 & 124 & 125 & 126 & 127 \\
\hline 128 & 129 & 130 & 131 & 132 & 133 & 134 & 135 & 136 & 137 & 138 & 139 & 140 & 141 & 142 & 143 \\
\hline 144 & 145 & 146 & 147 & 148 & 149 & 150 & 151 & 152 & 153 & 154 & 155 & 156 & 157 & 158 & 159 \\
\hline 160 & 161 & 162 & 163 & 164 & 165 & 166 & 167 & 168 & 169 & 170 & 171 & 172 & 173 & 174 & 175 \\
\hline 176 & 177 & 178 & 179 & 180 & 181 & 182 & 183 & 184 & 185 & 186 & 187 & 188 & 189 & 190 & 191 \\
\hline 192 & 193 & 194 & 195 & 196 & 197 & 198 & 199 & 200 & 201 & 202 & 203 & 204 & 205 & 206 & 207 \\
\hline 208 & 209 & 210 & 211 & 212 & 213 & 214 & 215 & 216 & 217 & 218 & 219 & 220 & 221 & 222 & 223 \\
\hline 224 & 225 & 226 & 227 & 228 & 229 & 230 & 231 & 232 & 233 & 234 & 235 & 236 & 237 & 238 & 239 \\
\hline 240 & 241 & 242 & 243 & 244 & 245 & 246 & 247 & 248 & 249 & 250 & 251 & 252 & 253 & 254 & 255 \\
\hline
\end{tabular}

Gambar 3. Modula Hasil Inisialisasi Sbox 
b. Menyimpan kunci dalam Key Byte Array

Pada tahapan ini, kunci (key) yang akan digunakan untuk mengenkripsi atau dekripsi akan dimasukkan ke dalam array berukuran 256 secara berulang sampai seluruh array terisi. Algoritmanya adalah sebagai berikut:

- isi j dengan 1 ,

- untuk $\mathrm{i}=0$ hingga $\mathrm{i}=255$ lakukan,

- jika j > panjang kunci maka,

- j diisi dengan nilai 1 ,

- akhir jika,

- isi k ke i dengan nilai ascii karakter kunci ke j,

- nilai j dinaikkan 1 ,

- tambahkan i dengan 1, kembali ke 2.

Dari algoritma tersebut akan didapatkan urutan array key misalkan sebagai berikut untuk kunci dengan panjang 8 karakter dengan urutan karakter dalam ASCII “109 97104989897104 ”.

\begin{tabular}{|l|l|l|l|l|l|l|l|l|l|l|l|l|l|l|l|}
\hline 109 & 97 & 104 & 97 & 98 & 98 & 97 & 104 & 109 & 97 & 104 & 97 & 98 & 98 & 97 & 104 \\
\hline 109 & 97 & 104 & 97 & 98 & 98 & 97 & 104 & 109 & 97 & 104 & 97 & 98 & 98 & 97 & 104 \\
\hline 109 & 97 & 104 & 97 & 98 & 98 & 97 & 104 & 109 & 97 & 104 & 97 & 98 & 98 & 97 & 104 \\
\hline 109 & 97 & 104 & 97 & 98 & 98 & 97 & 104 & 109 & 97 & 104 & 97 & 98 & 98 & 97 & 104 \\
\hline 109 & 97 & 104 & 97 & 98 & 98 & 97 & 104 & 109 & 97 & 104 & 97 & 98 & 98 & 97 & 104 \\
\hline 109 & 97 & 104 & 97 & 98 & 98 & 97 & 104 & 109 & 97 & 104 & 97 & 98 & 98 & 97 & 104 \\
\hline 109 & 97 & 104 & 97 & 98 & 98 & 97 & 104 & 109 & 97 & 104 & 97 & 98 & 98 & 97 & 104 \\
\hline 109 & 97 & 104 & 97 & 98 & 98 & 97 & 104 & 109 & 97 & 104 & 97 & 98 & 98 & 97 & 104 \\
\hline 109 & 97 & 104 & 97 & 98 & 98 & 97 & 104 & 109 & 97 & 104 & 97 & 98 & 98 & 97 & 104 \\
\hline 109 & 97 & 104 & 97 & 98 & 98 & 97 & 104 & 109 & 97 & 104 & 97 & 98 & 98 & 97 & 104 \\
\hline 109 & 97 & 104 & 97 & 98 & 98 & 97 & 104 & 109 & 97 & 104 & 97 & 98 & 98 & 97 & 104 \\
\hline 109 & 97 & 104 & 97 & 98 & 98 & 97 & 104 & 109 & 97 & 104 & 97 & 98 & 98 & 97 & 104 \\
\hline 109 & 97 & 104 & 97 & 98 & 98 & 97 & 104 & 109 & 97 & 104 & 97 & 98 & 98 & 97 & 104 \\
\hline 109 & 97 & 104 & 97 & 98 & 98 & 97 & 104 & 109 & 97 & 104 & 97 & 98 & 98 & 97 & 104 \\
\hline 109 & 97 & 104 & 97 & 98 & 98 & 97 & 104 & 109 & 97 & 104 & 97 & 98 & 98 & 97 & 104 \\
\hline 109 & 97 & 104 & 97 & 98 & 98 & 97 & 104 & 109 & 97 & 104 & 97 & 98 & 98 & 97 & 104 \\
\hline
\end{tabular}

Gambar 4. Hasil Pengacakan Sbox

2. Stream Generation / Pseudo Random Generation Algorithm (PRGA)

Pada tahapan ini akan dihasilkan nilai pesuodorandom yang akan dikenakan operasi XOR untuk menghasilkan ciphertext ataupun sebaliknya yaitu untuk menghasilkan plaintext. Algoritmanya adalah sebagai berikut:

- isi indeks i dan $\mathrm{j}$ dengan nilai 0 ,

- untuk $\mathrm{i}=0$ hingga $\mathrm{i}=$ panjang plaintext, isi nilai i dengan hasil operasi $(\mathrm{i}+1) \bmod 256$,

- isi nilai j dengan hasil operasi (j+s(i)) mod 256,

- tukar nilai s(i) dan $\mathrm{s}(\mathrm{j})$, isi nilai t dengan hasil operasi (s(i)+(s(j) $\bmod 256)) \bmod 256$,

- isi nilai y dengan nilai $\mathrm{s}(\mathrm{t})$, nilai y dikenakan operasi XOR terhadap plaintext,

- tambahkan i dengan 1 , kembali ke 2.

Dengan demikian akan dihasilkan ciphertext dengan hasil XOR antar sream key dari S-Box dan plaintext secara berurutan.

\section{HASIL DAN PEMBAHASAN}

Pada bagian ini berisi analisa, hasil serta pembahasan dari topik penelitian, yang bisa di buat terlebih dahulu metodologi penelitian. Bagian ini juga merepresentasikan penjelasan yang berupa penjelasan, gambar, tabel dan lainnya.

\subsection{Analisa Sistem}

Adapun analisa kebutuhan sistem adalah sebagai berikut :

1. Aplikasi dapat memberikan fungsi otentifikasi user melalui proses login.

2. Aplikasi dapat memberikan layanan proses enkripsi (pengacakan isi data).

3. Aplikasi dapat memberikan layanan proses dekripsi (mengembalikan isi data seperti semula).

4. Aplikasi dapat memberikan layanan kompresi (pemampatan data).

5. Aplikasi dapat memberikan layanan file jika telah melakukan proses ataupun dekripsi.

\subsection{Perancangan Enkripsi}

1. Tampilan Enkripsi 
Perancangan ini akan ditampilkan sebuah tabel dari database tabel_mahasiswa. Di bagian atas halaman, terdapat tombol yang digunakan untuk mengenkripsi data dari tabel tersebut. Rancangan tampilan dapat dilihat pada Gambar 5.

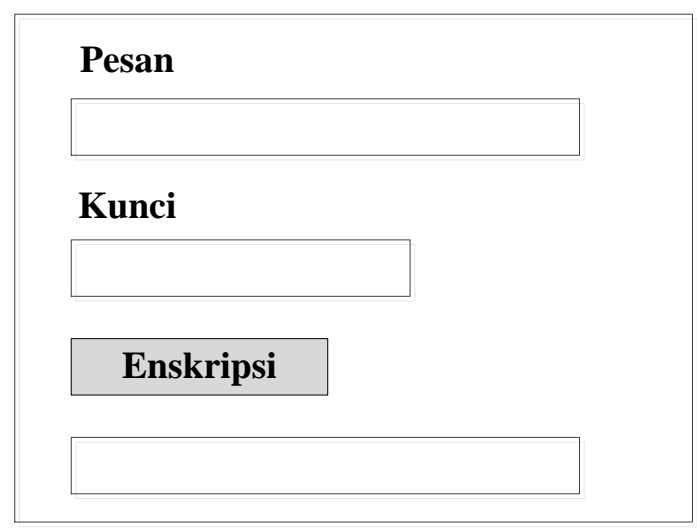

Gambar 5. Rancangan Tampilan Enkripsi

\section{Tampilan Deskripsi}

Perancangan ini akan ditampilkan sebuah tabel dari database tabel mahasiswa_enkripsi. Di bagian atas halaman, terdapat tombol yang digunakan untuk mendekripsi data dari tabel tersebut. Rancangan tampilan dapat dilihat pada Gambar 6.

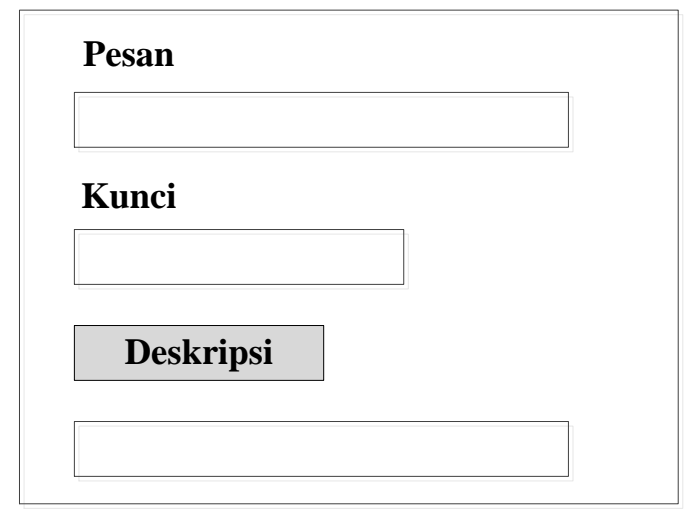

Gambar 6. Rancangan Tampilan Deskripsi

3. Hasil Enkripsi

Tahap ini merupakan pengujian dari keseluruhan tahap-tahap yang telah dilalui dimulai dari analisis kebutuhan hingga tahap implementasi. Pengujian dilakukan terhadap hasil enkripsi (ciphertext) pada database dan hasil dekripsi. Pengujian terhadap enkripsi dilakukan dengan memproses apakah sebuah data dapat disandikan sedangkan pengujian terhadap dekripsi dilakukan dengan memproses apakah data yang terenkripsi dapat diubah menjadi seperti semula. Pengujian terhadap hasil enkripsi juga melihat apakah hasil enkripsi (ciphertext) mempunyai ukuran data yang sama dengan pesan asli atau tidak.

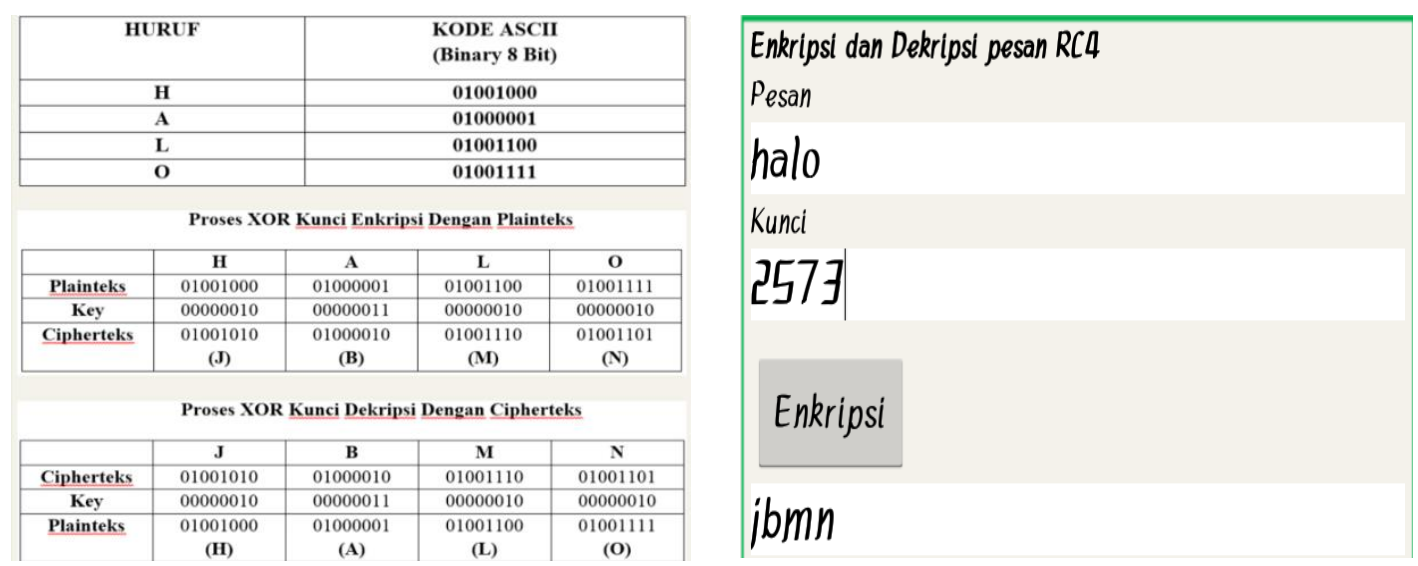

Gambar 7. Hasil Enkripsi Metode RC4 


\section{KESIMPULAN}

Dari uraian yang telah disampaikan pada bab-bab sebelumnya mengenai pengamanan file(teks) menggunakan Algoritma RC4 ini, maka dapat diambil kesimpulan sebagai berikut:

1. Perangkat lunak ini dikembangkan sebagai pengaman data atau file (teks) berbasis bilangan biner.

2. Teknik kriptografi merupakan teknik yang sangat berperan/penting dalam mengamankan data.

3. Pesan tersandikan (ciphertext ) yang dapat disisipkan ke dalam citra mempunyai nilai desimal tidak lebih dari 255 dalam kode ASCII dan belum ditemukan metode untuk memecahkan masalah tersebut.

4. Aplikasi Enkripsi dan Deskripsi dengan algoritma RC4 menggunakan sistem operasi windows 8 yang merubah sistemwindows32 yaitu bagian Shell32 [4].

\section{REFERENCES}

[1] M. Syahril and H. Jaya, "Aplikasi Steganografi Pengamanan Data Nasabah di Standard Chartered Bank Menggunakan Metode Least Significant Bit dan RC4,” Semin. Nas. Sains Teknol. Inf., pp. 505-509, 2019.

[2] A. P. Sutiono, “Algoritma RC4 sebagai Perkembangan Metode Kriptografi,” Bandung Inst. Teknol. Bandung, pp. 1-6, 2011.

[3] R. T. Jurnal, "Penerapan Algoritma Rivert Code 4 (Rc 4) Pada Aplikasi Kriptografi Dokumen,” Petir, vol. 11, no. 1, pp. 38-47, 2018, doi: 10.33322/petir.v11i1.6.

[4] J. Pseudocode, S. Informasi, U. M. Bengkulu, and H. Cipta, “Implementasi Algoritma Rc4,” vol. V, 2018. 